\title{
Mito e história de um posseiro do Brasil Colonial nos Sertões de Araraquara
}

\section{Mith and history of a land squatter in Colonial Brazil in Arararaquara's backlands}

Fransérgio Follis*

\begin{abstract}
Resumo
Analisando a farta documentação reproduzida, mas pouco explorada e analisada, pela bibliografia que aborda o povoamento dos extensos Sertões de Araraquara, esse artigo busca (re)construir a trajetória histórica do posseiro Pedro José Neto nessa região nas últimas décadas do período colonial. Para isso, entretanto, fez-se necessário desconstruir a versão histórica propagada por uma bibliografia regional ufanista e pouco científica, que baseada em especulações e hipóteses infundadas, transformou esse posseiro num mito dos sertões paulistas, um herói regional civilizador que contra todas as diversidades dos inóspitos sertões teria conquistado imensas porções de terras e se constituído no fundador da freguesia de Araraquara.
\end{abstract}

Palavras-chave: posseiros; sesmeiros; conflito de terras, Brasil Colonial, Sertões de Araraquara;

\begin{abstract}
Analyzing the abounding but not explored or analysed enough, reproduced documents about the settlement of Araraquara's extensive backlands, this article aims at (re)constructing the historical trajectory of the land squatter Pedro José Neto in this region in the last decades of the colonial period. To do so, however, it was necessary to deconstruct the historical version spread by an amateur and vanglorious regional bibliography, based on unfounded speculations and hypothesis, which transformed this land squatter in a backlands myth, a regional civilizing hero, which accounts for all the diversities of the inhospitable backlands. This hero would have conquered huge portions of lands, constituting himself on the founder of Araraquarara's pioneer village.
\end{abstract}

Keywords: land squatters; land grantees; land conflicts; Colonial Brazil; Araraquara Backlands.

\footnotetext{
* Doutor em Sociologia pela UNESP/Araraquara. Professor do Centro Universitário Central Paulista UNICEP.E-mail: follis25@gmail.com
} 


\section{Introdução}

Em grande parte das pequenas e médias cidades do interior do Brasil onde os trabalhos acadêmicos sobre a história regional ou local são raros, ou até mesmo inexistentes, predomina uma produção histórica tradicional elaborada por cronistas, memorialistas e escritores amadores que desconhecem os princípios teóricos e metodológicos básicos da produção do conhecimento histórico.

Nesse tipo de produção, os textos geralmente são simples narrativas cronológicas de ações políticas e econômicas de membros da elite da localidade, como autoridades políticas, grandes fazendeiros e empresários, que aparecem então como os únicos protagonistas da história, verdadeiros heróis promotores do progresso, da civilidade e do bem comum. Por outro lado, a presença de outros atores históricos, como escravos, negros alforriados, posseiros, camaradas, colonos e operários é minimizada ou simplesmente ignorada.

A falta de rigor científico e metodológico costuma produzir também confusões na análise e interpretação das informações presentes nos documentos e nas referências bibliográficas utilizadas, equívocos estes que são, muitas vezes, reproduzidos por outros autores, se consolidando enquanto verdades históricas. Ainda no campo metodológico, observa-se que quase sempre inexiste a preocupação de se estabelecer a relação do local ou regional com o contexto mais amplo. Dessa forma, a história regional aparece então "encerrada em si mesma", sem conexão com a dinâmica externa da qual sofre influências, "como um microcosmos que se basta e se auto-explica".

Essa historiografia amadora regional (ou local) apresenta também uma forte tendência ufanista, expressa na construção de um passado glorioso e heróico, digno de ser celebrado. Nesse sentido, todo progresso alcançado por uma região ou município é apresentado como resultado do esforço pessoal de personalidades históricas que dedicaram a vida em prol do bem coletivo. Em território paulista esses atores são inclusive associados à imagem heróica do bandeirante desbravador e civilizador. Muitas vezes, o propósito primordial desses autores amadores é eleger e construir o herói povoador da região, o herói fundador da cidade, os heróis promotores da civilização e do progresso. Por conseguinte, nesse tipo de produção quase sempre estão ausentes as contradições, a exploração do homem pelo homem, o monopólio do poder

\footnotetext{
${ }^{1}$ PESAVENTO, Sandra Jatahi. História regional e transformação social. In: SILVA, Marcos (org.). República em Migalhas - História Regional e Local. São Paulo: Marco Zero, 1990. pp. 69-70.
} 
por parte de um grupo ou classe, os conflitos e as injustiças, o favoritismo, os interesses políticos e econômicos particulares, e os privilégios de todo tipo.

Dessa forma, escrever ou reescrever a história de muitas regiões e localidades brasileiras de maneira crítica e desmistificadora, e segundo os princípios metodológicos científicos, é uma necessidade premente. Conforme ressalta Rodrigues, faz-se necessário “[...] Avançar para além do amadorismo, das simples biografias, dos relatos de casos, das efemérides ou das abordagens políticas e econômicas de uma dada localidade". ${ }^{2}$

Norteado por esse objetivo, pretende-se, nesse texto, reescrever a história do posseiro Pedro José Neto nos Sertões de Araraquara no final do período colonial. Mais precisamente, trata-se de desconstruir o mito criado e consolidado em torno desse personagem dos sertões paulistas transformado em herói pela historiografia regional.

Para esse propósito, analisamos as informações e a farta documentação que encontramos reproduzida, mas pouco explorada e analisada, nos trabalhos de pesquisadores amadores que escreveram sobre o povoamento dos Sertões de Araraquara. A esse respeito é válido ressaltar que o historiador de ofício não deve descartar a bibliografia amadora regional, pois costuma trazer informações, relatos e transcrições de documentos históricos que, devidamente confrontados e analisados, podem ser de grande importância na (re)construção da história regional e local sob um viés científico.

Para buscar o objetivo traçado, optamos por desenvolver o texto em três tópicos. No primeiro tópico, intitulado Apossamento de terras no Brasil Colonial, buscamos historicizar o surgimento e o desenvolvimento da prática do apossamento, paralelamente à política de distribuição de terras mediante doações de sesmarias estabelecida pela Coroa portuguesa. Buscou-se, assim, entender as características dos apossamentos no contexto mais amplo do processo de apropriação de terras e povoamento do território brasileiro no período colonial, o que muito nos auxiliou no entendimento posterior do processo de apropriação de terras nos Sertões de Araraquara. No tópico dois, Os Sertões de Araraquara, procurou-se caracterizar no espaço e no tempo a região estudada, especialmente no momento em que se tem início a sua ocupação. ${ }^{3}$

\footnotetext{
${ }^{2}$ RODRIGUES, Jane de Fátima Silva. História Regional e local: problemas teóricos e práticos. In: História e Perspectivas. Uberlândia, 1997, n. 16/17, p. 152.

${ }^{3}$ Para expormos o que eram os Sertões de Araraquara, partimos do mesmo entendimento de Barbosa, ou seja, que a definição de uma região "[...] vale-se, criteriosamente, da observação das relações orgânicas que determinada espacialidade mantém com outra em diferentes momentos históricos. Desta maneira, a noção de espaço local ou regional é flexível e suas modificações derivam dos movimentos e do curso da história." BARBOSA, Agnaldo de Sousa. A propósito de um estatuto para a história local e regional: algumas
} 
No tópico três, A saga de Pedro José Neto: desconstruindo o mito, construindo a história, baseando-se nas informações e especialmente nas fontes documentais reproduzidas ipsis litteris presentes na bibliografia amadora sobre a região, procuramos demonstrar a inconsistência e incoerência dos argumentos utilizados para transformar Pedro José Neto num herói regional e, em seguida, apresentar a história objetivamente fundamentada de sua interessante trajetória nos Sertões de Araraquara.

\section{Apossamentos de terras no Brasil Colonial}

Objetivando regulamentar a apropriação das terras recém-descobertas na América e viabilizar sua colonização, a Coroa Portuguesa instaurou no Brasil o instituto das sesmarias, ordenamento jurídico de distribuição de terras que permaneceu em vigor durante todo o período colonial, já que somente foi revogado no ano de 1822, um pouco antes de Dom Pedro I proclamar a independência da colônia.

Segundo a lei do sesmarialismo, as porções de terras deveriam ser doadas gratuitamente, ou seja, sem nenhum tipo de taxa ou imposto, mas sob a condição do sesmeiro tornar a gleba recebida produtiva dentro do prazo máximo de cinco anos, caso contrário as autoridades coloniais deveriam, em nome da Coroa portuguesa, retomar a terra doada sem nenhuma indenização. As Ordenações do Reino orientavam também para não se doar porções de terra além da capacidade produtiva do requerente. $O$ sesmeiro também se obrigava a fazer a demarcação legal das terras, abrir ou conservar caminhos, construir pontes e outros melhoramentos no sentido de propiciar o trânsito público.

Preocupada em estimular o povoamento da colônia e evitar gastos com a administração colonial, na prática, entretanto, a Coroa portuguesa manteve uma política de liberalidade em relação ao tamanho das glebas doadas e ao cumprimento estrito das normas do sesmarialismo.

Essa postura se afinava com a maneira pela qual os colonizadores portugueses pensaram e conceberam a colonização do Brasil. O objetivo era extrair do Brasil o máximo de lucro, com o mínimo de investimentos, o que significava renunciar às normas imperativas e absolutas e ceder às conveniências imediatas. ${ }^{4} \mathrm{O}$ resultado foi o desrespeito às normas e, conseqüentemente, a proliferação de grandes latifúndios pouco ou nada produtivos.

reflexões. In: História \& Perspectivas. Uberlândia, n. 20/21, pp. 124-125.

${ }^{4}$ A respeito da mentalidade colonial portuguesa no Brasil ver: HOLANDA, Sérgio Buarque de. Raízes do Brasil. 26 ed. São Paulo: Companhia das Letras, 1995. 
Tendo em vista o desinteresse da metrópole em fiscalizar e fazer valer a lei do sesmarialismo, na prática as autoridades coloniais desprezaram as recomendações legais e fizeram doações de imensas sesmarias aos membros da classe dominante colonial. Eram feitas doações de quatro, cinco, dez e até vinte léguas quadradas. Alguns privilegiados recebiam mais de uma sesmaria ou conseguiam doações para vários membros da família. No início da colonização, o recebimento de mais de uma sesmaria não era considerado ilegal. Como a venda da terra recebida também não era impedida pela legislação, alguns sesmeiros aproveitavam para vender inteira, ou em pedaços, a sesmaria recebia.

Além disso, os limites das terras anotados pelas cartas de datas eram muito imprecisos e os métodos de medição e demarcação eram bastante rudimentares. Tudo isso facilitou a incorporação de novas porções de terras por sesmeiros oportunistas, o que contribuiu para aumentar o tamanho das propriedades. Isso ocorria mediante a ocupação de terras devolutas, apossadas por outrem e mesmo de outra sesmaria. Essa prática acabou provocando vários conflitos de terra, em que quase sempre predominou a lei do mais forte. Assim, na maioria das vezes levava vantagem o proprietário de maior poder econômico e político.

Em regra, a concessão de sesmarias estava restrita às pessoas mais influentes e ricas da colônia. Os homens de parcos recursos tinham poucas chances de conseguir uma sesmaria, já que para esses as autoridades coloniais eram muito mais cuidadosas na observação da lei, que dentre outras coisas exigia que o requerente comprovasse possuir meios capazes de tornar a terra pleiteada produtiva, o que demandava considerável número de escravos.

Outra possibilidade de se tornar proprietário de terras no Brasil Colonial era a compra de uma gleba junto aos não raros sesmeiros que vendiam suas sesmarias inteiras ou em partes. Logicamente estavam excluídos dessa possibilidade os homens mais pobres.

Assim, para a camada mais pobre da sociedade colonial, o acesso à terra esteve praticamente restrito a uma única possibilidade: a realização de um apossamento, ocupação pura e simples de terras devolutas ou das não raras glebas de sesmarias recebidas e não ocupadas por seus donatários. Dessa forma, vários desses homens modestos - que se viram impossibilitados de ter acesso à terra gratuitamente por meios legais, isto é, mediante uma carta de sesmarias - se dirigiram para as áreas despovoadas do interior do território colonial em busca de terras vagas que pudessem ser apropriadas. Como destaca Ruy Cirne Lima: 
Neste regime latifundiário, porém, em que o cultivador independente, o lavrador livre, é economicamente asfixiado, vê-se, então, o apossamento pelos colonos dos tratos de terreno, deixados entre os limites das grandes propriedades, e assiste-se à imigração dos mais audazes, para as paragens distantes dos núcleos de povoamento, em demanda de terras que, de tão remotas, ao senhor de fazendas lhe não valha ainda a pena requerer de sesmaria. ${ }^{5}$

Sem deixar de existir na forma de propriedade de menor dimensão voltada para as atividades de subsistência ou de fornecimento de gêneros para o mercado interno, por vezes as posses, pelos mesmos motivos que levaram à falta de controle no tamanho das sesmarias, assumiram também a feição de latifúndio, pois, sem fiscalização efetiva, seus limites acabavam sendo definidos pelo próprio posseiro. Ademais, para a pecuária extensiva colonial exercida em pastos naturais, atividade bastante utilizada por posseiros de poucos recursos em razão de exigir menos capital que o engenho açucareiro, a grande propriedade era até mesmo uma necessidade em razão da busca contínua por campos de pastagens.

Destarte, a prática do apossamento conviveu lado a lado com a doação de cartas de sesmarias desde o início da colonização, mas se intensificou no século XVIII com a ocupação de grandes áreas interioranas para a atividade pastoril. As terras devolutas eram mais abundantes no interior do território, pois aí as grandes culturas voltadas para a exportação, como a monocultura da cana-de-açúcar, se mostravam menos viável economicamente. Ademais, nos primeiros séculos de colonização, as autoridades coloniais relutavam em conceder sesmarias nas regiões mais afastadas da faixa litorânea, pois temiam perder o controle sobre áreas ainda desconhecidas que poderiam abrigar metais preciosos e pau-brasil. A Coroa cultivava também grande receio de que o deslocamento da população para o interior provocasse o despovoamento do litoral, deixando a colônia vulnerável às invasões estrangeiras. ${ }^{6} \mathrm{Com}$ isso, mesmo se tratando de uma prática ilegal e sempre sujeita a contestação, conforme bem observou José de Souza Martins, "sendo as terras devolutas abundantes, [...] a ocupação era expediente simples e eficaz".?

No princípio, a legislação portuguesa não reconhecia o apossamento. Portanto, era bastante comum a doação de sesmarias em áreas já ocupadas

\footnotetext{
${ }^{5}$ LIMA, Ruy Cirne. Pequena história territorial do Brasil: sesmarias e terras devolutas. Goiânia: Editora UFG, 2002, p. 48.

${ }^{6}$ Vale lembrar que as bandeiras se constituíam num desafio às leis portuguesas que procuravam restringir a ocupação do interior do território nos primeiros séculos de colonização. HOLANDA, op. cit., pp. 101-102.

${ }^{7}$ MARTINS, José de Souza. O cativeiro da terra. 3a. edição. São Paulo: Hucitec, 1986, p. 25.
} 
por posseiros. Também não era raro o antigo donatário de uma sesmaria abandonada e apossada por outrem procurar reavê-la, mesmo depois de ultrapassado em muito o prazo de cinco anos previsto pela lei do sesmarialismo para que a terra fosse devidamente ocupada e tornada produtiva. Nesses casos, munido da carta de sesmaria, o donatário requeria a propriedade impondo ao posseiro um acordo quase sempre prejudicial a esse último, como uma pequena indenização pelo roçado e outras benfeitorias que tivesse realizado. Em alguns casos em que a negociação era resolvida pacificamente, ocorria até mesmo a incorporação do posseiro como funcionário da propriedade. Quando o posseiro resistia às propostas nada compensatórias do antigo sesmeiro e às tentativas de expulsão, o conflito se estabelecia por meio da Justiça ou, como era mais comum, simplesmente por meio da força.

Apesar das Ordenações Philipinas do Reino de Portugal permitirem a aquisição de terras por mera ocupação, nas contendas entre sesmeiros e posseiros o ganho de causa quase sempre era dado aos primeiros, pois esses geralmente eram pessoas de maior poder econômico e político, que melhor conhecimento tinha dos caminhos legais e ilegais para a legalização de terras. Ademais, ao contrário da maioria dos posseiros pobres, esses homens de prestígio e recursos contavam também com o apoio de advogados e de autoridades, além de possuir mais armas de fogo e jagunços.

Era comum também os sesmeiros se aproveitarem da fragilidade dos posseiros e da imprecisão da demarcação dos limites das próprias sesmarias para expandir as fronteiras de suas terras sobre as glebas de posseiros vizinhos, iniciando, assim, vários conflitos de divisas. Não por acaso, muitos posseiros, assim que se sentiam ameaçados, procuravam legalizar as terras que ocupavam mediante a solicitação de uma carta de sesmaria à autoridade competente. Nessa solicitação, o posseiro declarava já estar ocupando e produzindo na gleba devoluta pleiteada, informando também os recursos que dispunha para torná-la produtiva, ou seja, a força de trabalho sob o seu domínio, geralmente comprovada pelo número de escravos e agregados. Mesmo assim, quando se tratava de homens pobres, as dificuldades se faziam presentes. Nesse caso, para confirmar as informações colocadas na solicitação da sesmaria, fazia-se necessário a apresentação de testemunhas de reconhecido prestígio social e político. Além disso, conforme assinalou Cincinato Braga, dado a sua fragilidade, "não raro o posseiro alienava seus direitos possessorios a outrem que melhores elementos tivessem para obter carta de sesmeiro". ${ }^{8}$

${ }^{8}$ BRAGA, Cincinato. Contribuição ao estudo da história e geografia da cidade e município de São Carlos do Pinhal. São Carlos: ASSER, 1994, p. 6 [grifos do autor]. 
Ao longo do século XVIII, o apossamento com cultura efetiva se tornou um costume e se estabeleceu como um modo de aquisição de domínio, firmando-se cada vez mais como um direito consuetudinário, ainda que não reconhecido pela Coroa Portuguesa.

\section{Os Sertões de Araraquara}

É a partir no último quartel do século XVIII, como conseqüência da decadência das minas de ouro de Minas Gerais, Mato Grosso e Goiás, e da expansão da pecuária pela capitania de São Paulo, que se tem início a apropriação da terra e o povoamento dos chamados Sertões de Araraquara.

A expressão Sertões ou Campos de Araraquara servia para designar uma extensa área que se principiava na margem direita do rio Piracicaba, nas proximidades da sua confluência com o Rio Tietê, e se estendia ao longo da grande faixa compreendida entre os rios Tietê e Mogi-Guaçu até atingir o Rio Grande no sentido norte (divisa com o atual estado de Minas Gerais) e o rio Paraná no sentido noroeste (divisa com o atual estado de Mato Grosso do Sul). Os Sertões ou Campos de Araraquara eram, portanto, a designação genérica e maleável produzida pela memória coletiva para uma imensa área situada no planalto ocidental paulista, território cujo interior se manteve pouco conhecido até as últimas décadas do século XVIII, em contraponto à região da margem esquerda do rio Piracicaba, mais trilhada e conhecida dos paulistas.

Com base nas informações contidas nas primeiras sesmarias doadas na região, foi possível perceber que, entre as últimas décadas do século XVIII e as primeiras décadas do XIX, os povoadores definiam o início desses extensos sertões a partir da área despovoada que se principiava logo adiante do povoado de Piracicaba, núcleo urbano fundado em 1767 que durante um longo período foi "boca de sertão", ou seja, porta de entrada para os ermos Sertões de Araraquara. 
Mapa 1 - Sertões de Araraquara. ${ }^{9}$

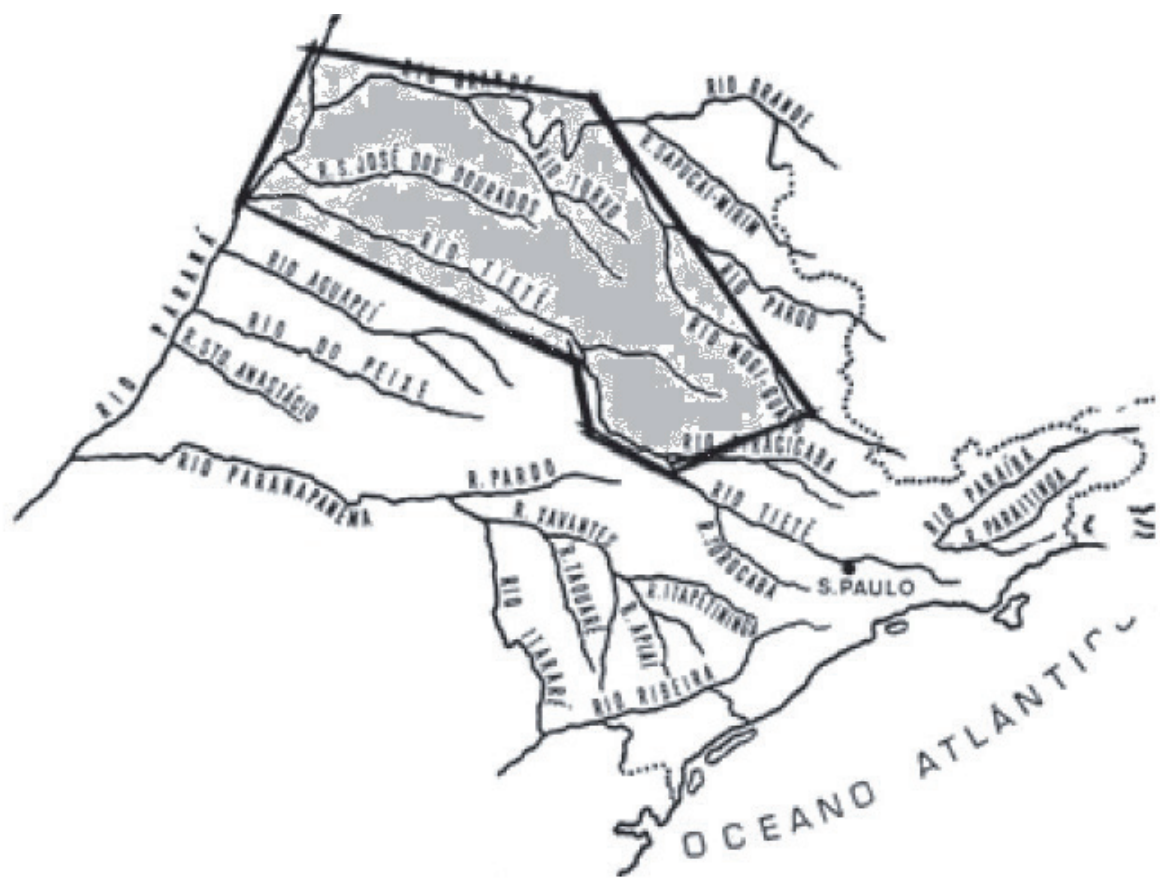

Datam do início do século XVII os primeiros relatos de incursões nesses sertões por parte dos bandeirantes. Já nesse século, o curso do Rio Tietê, limite meridional dessa extensa região, foi se tornando cada vez mais conhecido, pois um dos principais caminhos utilizado pelos paulistas para atacar e aprisionar indígenas das missões jesuíticas espanholas do Guairá era justamente o percurso fluvial pelo Tietê até sua foz no rio Paraná, e daí para o sul percorrendo a bacia Paraná-Paraguai. ${ }^{10}$

O primeiro caminho por terra foi construído somente em 1725 , quanto, Luís Pedroso de Barros, por solicitação do governador de São Paulo, abriu uma picada que atravessava o interior dos Sertões de Araraquara e chegava até o rio Paraná. Esse caminho, entretanto, não se consolidou. Não atraiu viajantes para as minas de Cuiabá e muito menos povoadores para os Sertões de Araraquara,

\footnotetext{
${ }^{9}$ Mapa extraído de: MANO, Marcel. Os campos de Araraquara: um estudo de história indígena no interior paulista. Tese (Doutorado em Ciências Sociais) - Instituto de Filosofia e Ciências Humanas, Universidade Estadual de Campinas, 2006, p. 12.
}

${ }^{10}$ Ibidem, p. 51. 
o que seria de fundamental importância para a sua manutenção. ${ }^{11}$ A nosso ver, o seu fracasso se deu especialmente em razão da preferência dos viajantes, tropeiros e povoadores, pela Estrada dos Goiases (ou do Anhanguera), caminho que durante o século XVIII se consolidou como a principal via de acesso às minas de Goiás e Mato Grosso, se constituindo também na principal rota de penetração para o interior do território paulista a partir das regiões mais povoadas da província de São Paulo. ${ }^{12}$

Desprezado o caminho para Cuiabá pelos Sertões de Araraquara, até as últimas décadas do século XVIII essa extensa região manteve a sua condição de sertão, sendo habitada ou visitada apenas por tribos indígenas e, provavelmente, por quilombolas e aventureiros à procura de metais e pedras preciosas. ${ }^{13}$ Foi nessa época que as autoridades coloniais voltaram a manifestar o interesse em abrir um caminho por terra até Mato Grosso e Goiás pelos Sertões de Araraquara. Para Neves, a construção desse novo caminho tinha como finalidade "socorrer os viajantes que se destinassem a Cuyabá e Matto Grosso, facilitar as diligencias do Real Serviço e promover a prompta e efficaz comunicação com as fronteiras, quando se restabelecessem em segurança do Estado". ${ }^{14}$

Dessa vez, a tarefa de construir um caminho que, partindo de Piracicaba, chegaria até a margem direita do rio Paraná, foi confiada ao sargento-mor da vila de Itu Carlos Bartholomeu de Arruda. A abertura dessa via interessava pessoalmente a Bartholomeu de Arruda, visto ser ele, à época, proprietário de duas sesmarias na região, uma adquirida junto à Coroa, em dezembro de

\footnotetext{
${ }^{11}$ A esse respeito, observa-se que, em 1730, muito provavelmente para se precaver do contrabando do ouro, a Coroa Portuguesa baixou uma lei condenando a utilização desse caminho. CAMARGO, Theodorico Leite de Almeida. Breve notícia histórica e geográphica sobre a cidade e município de S. Carlos. In: CASTRO, Franklin (org.). Almanach-Album de São Carlos 1916-1917. São Carlos-SP: Typographia Artística, 1917. p. 5; LEMOS, Alberto. História de Araraquara. Araraquara: Museu Histórico e Pedagógico Voluntários da Pátria; Prefeitura Municipal de Araraquara, 1972, p. 75.

${ }^{12}$ Segundo Bacellar e Brioschi, o traçado da Estrada dos Goiases “devia ser bem conhecido e relativamente livre de empecilhos no ano de 1722, quando a bandeira de Bartolomeu Bueno da Silva levou 'apenas 20 dias para chegar ao rio Grande, com dois dias e percursos diários de 24 a 26 quilômetros, englobando as passagens dos rios'. A população indígena foi sendo afastada e a 'frente civilizadora' avançava, deixando atrás de si uma população dedicada a uma cultura do excedente, produzindo para o próprio consumo e exercendo o comércio com os viajantes. BACELLAR, Carlos de Almeida Prado; BRIOSCHI, Lucila Reis (orgs.). Na Estrada do Anhanguera: uma visão regional da história paulista. São Paulo: Humanitas FFLCH/USP, 1999, p. 47.

${ }^{13}$ A esse respeito ver: MANO, op. cit.; e NEVES, Ary Pinto das. São Carlos do Pinhal no século XIX. Iguape: Gráfica Soset, 1997.
}

${ }^{14}$ NEVES, op. cit., p. 14. 
1785, e outra comprada do Cirurgião-Mor Manuel dos Santos Rêgo, em março de $1786 .{ }^{15}$

Tendo em vista as ações para a abertura desse novo caminho e o processo de expansão da pecuária pelo interior do território paulista no último quartel do século XVIII, tem início a apropriação de terras nos Sertões de Araraquara mediante apossamentos e concessão de sesmarias. Em 1781 foram concedidas as primeiras três cartas de sesmarias na região.

A partir desse momento, os Sertões de Araraquara passaram a atrair migrantes paulistas e mineiros à procura de pastagens naturais para a criação de gado. Não por acaso, a maioria dos pedidos de sesmaria na região era acompanhada da justificativa "para criar gado", e as terras requeridas geralmente eram de campos, e não de matas. Nos censos populacionais efetuados entre os anos de 1809 e 1811, a pecuária aparece como a principal atividade dos moradores. ${ }^{16}$

Nas primeiras décadas de povoamento, ao lado da criação de gado, principal atividade dos moradores, a população desenvolvia também uma economia de subsistência baseada especialmente na produção de milho, arroz e feijão. Além desses produtos, os censos de 1809 a 1811 registraram a produção de algodão. Destacavam-se também a criação de porcos, a produção de queijos, mel e cera de abelha, além do cultivo do fumo, produtos que ao lado do algodão e da criação de gado vacum e cavalar eram comercializados com outras regiões, sobretudo com Piracicaba, vila produtora de açúcar que "funcionava como mercado consumidor e distribuidor dos produtos dos Campos de Araraquara." De Piracicaba e outras localidades vinham, dentre outros vários produtos, ferramentas e o necessário sal para o gado. ${ }^{17}$

É nesse contexto, do início do século XIX, que ocorrerá a progressiva valorização e o aumento do interesse e da luta por terras nos Sertões de Araraquara. Dada dessa época a vinda de Pedro José Neto para a região, posseiro que foi transformado num verdadeiro mito da história regional.

\section{A saga de um posseiro: desconstruindo o mito, construindo a história}

Não é tarefa fácil desvendar a história dos inúmeros homens e mulheres de parcos recursos do período colonial que impossibilitados de ter acesso à

\footnotetext{
${ }^{15}$ TRUZZI, Owaldo; FOLLIS, Fransérgio. A ocupação dos sertões de Araraquara: das sesmarias e apossamentos à Lei de Terras de 1850. São Carlos: EduFSCar, 2012.

${ }^{16}$ CORRÊA, Anna Maria Martinez. História social de Araraquara (1817 a 1930). Dissertação (Mestrado em História Social). São Paulo: FFCL-USP, 1967, p. 30.

${ }^{17}$ Ibidem, p. 57.
} 
terra pelos meios legais estabelecidos pelo sistema de sesmarias passaram a buscá-la e a ocupá-la nas regiões despovoadas do interior do território. Isso porque quase sempre são raros os vestígios deixados pela maioria desses posseiros.

O caso de Pedro José Neto, homem que, juntamente com sua família, se dirigiu para as terras dos Sertões de Araraquara na primeira década do século XIX, consta entre as exceções, pois sobre esse posseiro existem fontes documentais que nos permitem traçar a sua trajetória na região.

Apesar disso, a maior parte dos escritores que abordou a trajetória de Pedro José Neto nos Sertões de Araraquara cometeu vários equívocos. Alguns pelo intuito de transformar Pedro José Neto num mito, uma espécie de herói da região ou, pelo menos, do município de Araraquara. Outros simplesmente por repetir e, em alguns casos, até mesmo incrementar, sem maiores preocupações e questionamentos, a versão construída pelos primeiros. Ao comentar a questão, Alberto Lemos, um dos raros críticos que ousou contestar a saga consagrada de Pedro José Neto nos Sertões de Araraquara, fez as seguintes observações:

\footnotetext{
A respeito dessa histórica figura de sertanista, circulam versões que, oriundas de idéias arraigadas no espírito de desinformados pesquisadores, sistemática e reiteradamente repetidas com o perpassar do tempo, ganharam consistência de dogma, e como tal se apresentam enquistadas na história de Araraquara. [...] nota-se que as informações são, invariavelmente, transmitidas sem qualquer suporte de prova documental. O que se escreve e repete apóia-se sempre em vaga e inconsistente tradição. ${ }^{18}$
}

Acreditamos que a heroificação de Pedro José Neto esteja relacionada ao fato dele ter sido eleito o fundador da cidade de Araraquara por aqueles que primeiro escreveram sobre o assunto. Em razão disso, ele foi, e ainda continua sendo, descrito como um desbravador destemido que, contra todas as adversidades, trouxe a civilização e abriu caminho para o futuro progresso nos Sertões de Araraquara, façanha coroada em 1817 com a criação do primeiro núcleo urbano dessa região, a freguesia de São Bento de Araraquara, símbolo maior da instalação da civilização nos sertões.

Mas quais as justificativas apresentadas para se atribuir a Pedro José Neto o honroso título de fundador de Araraquara, em detrimento de tantos outros que participaram do processo de criação da freguesia? A seu favor, é apresentado o fato de ter participado da construção da capela de madeira

${ }^{18}$ LEMOS, op. cit., p. 84. 
necessária para que a freguesia fosse fundada. José Ferrari Secondo lhe atribui também o mérito do envio da solicitação de criação da freguesia às autoridades competentes da Colônia ${ }^{19}$, o que, entretanto, a documentação existente não comprova. Tampouco foi Pedro José Neto quem doou as terras para o patrimônio da Igreja, outro pré-requisito para a fundação de freguesias no Brasil colonial. ${ }^{20}$

Acreditamos que a concessão do mérito de fundador de Araraquara a Pedro José Neto esteja fortemente ligada também à comoção provocada pelo fato do mesmo ter falecido poucos dias após a emissão do alvará régio de criação da freguesia. 0 título de fundador da freguesia seria então uma homenagem póstuma em razão dos trabalhos prestados por ele em prol das obras necessárias para a fundação do lugarejo, como a construção da capela. Segundo o autor José Ferrari Secondo, o vigário da freguesia de Araraquara, Francisco Manoel Malachias, por despacho real de 22 de setembro de 1818, acrescentou no registro de óbito de Pedro José Neto a seguinte frase: "fundador desta Matriz". ${ }^{21}$

No percurso de construção do mito, a própria chegada de Pedro José Neto aos Sertões de Araraquara foi transformada numa saga carregada de simbolismo que muito vem contribuindo para a sua consagração como herói. Os trechos que selecionamos a seguir, escritos por José Ferrari Secondo, um dos primeiros a abordar a trajetória de Pedro José Neto na região, e que se constituiu numa das principais referências sobre o tema para os autores que vieram depois, são ilustrativos a esse respeito.

Pedro José Neto, destemido fluminense, era na sua época, homem de cultura, trabalhador, de trato muito brando e entendido em medicina caseira, grangeando por sua bondade a simpatia do "gentio". Com o concurso de seus escravos e alguns índios mansos, pôde conquistar e abrir todas as posses dêste "hinterland" que hoje abrange vários municípios, cinco comarcas e dois bispados.

[...] Em 1780, com vinte anos de idade, moço forte e destemido, disposto a lutar, cheio de esperança, foi à freguesia de Piedade da Borda do Campo, hoje cidade de Barbacena, Minas Gerais, época aurea de mineração, e, trabalhando, conseguiu acumular algumas economias, consorciando-se a 12 de Agôsto de 1784, com D. Ignacia Maria, também fluminense, filha do Capitão Francisco Ferreira da Silva,

\footnotetext{
${ }^{19}$ SECONDO, José Ferrari apud ALMEIDA, Nelson Martins et al. Estudo histórico e geográfico da cidade e município de Araraquara. In: ALMEIDA, Nelson Martins (org.). Álbum de Araraquara. Araraquara, 1948, p. 22.

${ }^{20}$ Para a fundação da Freguesia de São Bento de Araraquara foram doadas quatrocentas braças em quadra da sesmaria do Ouro, pertencente à época ao padre Joaquim Duarte Novais. CORRÊA, op. cit., p. 30.

${ }^{21}$ SECONDO apud ALMEIDA et al., op. cit., p. 23.
} 
senhora de raras virtudes e companheira dedicada de seu espôso em tôdas as peripécias da vida, cuja época era só de lutas com índios não civilizados.

[...] Em 1787, Pedro José Neto com seus dois filhos e espôsa, transferiu residência para a cidade de Itú [...]. Com suas pequenas economias abriu uma fazenda de criar e cultura de cereais.

Mas a sua estadia em Itú foi curta. No ano de 1790, a política local estava muito agitada e Pedro José Neto teve uma discussão que resultou em conflito, e tendo esbofeteado um seu rival, foi processado pela Justiça de Itú, sendo condenado ao degrêdo em Piracicaba, pelo então célebre Capitão-Mór de Itú, Vicente Taques Goes de Aranha. Conseguiu, porém, fugir, transpondo a margem posta do Piracicaba, e embrenhando-se pelo sertão impenetrável, escapou à justiça. Diante das matas de São Carlos, junto ao "Pinhal", o fugitivo estacou incerto e receioso, não se atrevendo a avançar mais no emaranhado da selva, cujo término era tão desconhecido; entretanto, dias após, observou que uma longínqua pluma de fumaça se elevara para além da mata, como indício de vida humana, do outro lado da fronteira verde.

Aqui a crônica reza... e então raciocinou com a prática que tinha: "Se tem fogo, tem campo", e penetrou na mata". Com admiração sua, saiu logo nos campos, onde em 1856, Jesuino Soares de Arruda fundava a cidade de São Carlos do Pinhal, verificando que as matas que êle julgava intermináveis eram pequenas, e aos poucos, foi-se internando até "Monte Alegre" e "Bonfim" [denominação de futuras sesmarias concedidas na região].

Fixando-se nos Campos de Araraquara, da mais decantada salubridade, Pedro José Neto estabeleceu as posses de Ouro, Rancho Queimado, Cruzes, Lageado, Cambuy, Bonfim e Monte Alegre.

Mais tarde, em breve decurso de anos, outros exploradores vieram dar nestas paragens; com a condição de o livrarem da justiça de Itú, Pedro José Neto cedeu à divisa a maior parte das terras que possuía: ao Major Duarte vendeu Monte Alegre e fez doação das posses do Ouro, Cruzes e Rancho Queimado; a João Manoel do Amaral, a do Bonfim, a Domingos Soares de Barros, a do Lageado, demarcada em 12 de outubro de 1812; e ao Coronel Joaquim de Moraes Leme, a do Cambuy.

[...] Em vista dos seus grandes serviços prestados no desbravamento do Sertão de Aracoara, Pedro José Neto conseguiu o seu perdão; e assim, livre de culpa, pôde em 1804, ir com sua mulher Ignacia Maria, à então incipiente vila de Campinas, nomear um procurador para legalizar as suas posses. Depois requereu ao Governo Carta de Sesmaria que lhe foi concedida em 7 de Julho de 1811 [...]. No ano de 1805, Pedro José Neto e seus dois filhos, construíram a capelinha do nascente Bairro de Araraquara. Terminada a primeira ermida, dirigiu um requerimento ao Govêrno Eclesistico, pedindo que a sua capela do Bairro de Araraquara fosse erecta em freguesia desmembrada de Piracicaba. O requerente alegava que a distância da freguesia de Piracicaba era muito grande e um padre não podia vir até Araraquara; era viagem penosa e haviam muitas onças no trajeto. 
[...] Infelizmente, Pedro José Neto não pôde compartilhar da alegria dos moradores do Bairro, vindo a falecer vinte dias depois, repentinamente, de coice de burro, em 19 de Novembro de $1817 .{ }^{22}$

Secondo atribui a Pedro José Neto qualidades enobrecedoras e façanhas que constroem sua condição de herói e protagonista da história dos sertões e da fundação da cidade de Araraquara. Nesse processo, igualmente sua esposa recebe qualidades consideradas raras: "senhora de várias virtudes e companheira dedicada de seu espôso", a aliada ideal para seus inúmeros feitos.

Imbuído do mesmo propósito de transformar Pedro José Neto num herói regional, Theodorico Camargo relata que para fugir da Justiça este teria atravessado o rio Piracicaba a nado e caminhado até as terras que hoje pertencem ao município de São Carlos, região dos Sertões de Araraquara onde ele teria primeiro se fixado. ${ }^{23}$ Entretanto, não existe nenhuma prova documental que confirme a versão de que Pedro José Neto era de fato um foragido da Justiça, sequer o suposto crime e condenação são comprovados. ${ }^{24}$ Ao contrário, as informações contidas no recenseamento de 1809, realizado dois anos após a chegada de Pedro José Neto à região - ocorrida em $1807^{25}$, indicam que o futuro posseiro veio para os Sertões de Araraquara acompanhado da esposa, dos filhos José da Silva (16 anos) e Joaquim Ferreira Neto (10 anos) e, provavelmente, do agregado Francisco de Paula, trazendo por certo também alguma bagagem..$^{26}$ Portanto, tudo indica que sua vinda para os Sertões de Araraquara teria sido minimamente planejada, e não em fuga desesperada, como afirma a grande maioria dos autores que abordou o tema.

A saga de Pedro José Neto ganha versão ainda mais fantasiosa e heróica na hipótese nada plausível de Telarolli. ${ }^{27}$ Baseando-se na informação equivocada de que o posseiro teria nascido em São João Del Rei, Minas Gerais, ${ }^{28}$

\footnotetext{
${ }^{22}$ SECONDO apud ALMEIDA et al., op. cit., pp. 22-23.

${ }^{23}$ CAMARGO, op. cit., p. 8.

${ }^{24}$ A esse respeito, Lemos comentou o seguinte: “[...] empreendemos diversas averiguações, sem qualquer êxito. Escritos, remotos ou atuais, que de modo expresso, com o valor de prova, se referissem a crime praticado por Pedro José Neto, ou a processo em que estivesse envolvido, não foram localizados.” “[...] Até hoje não foi encontrado processo criminal condenatório de Pedro José Neto em Itu, apesar de inúmeras buscas realizadas por vários pesquisadores, e tudo quanto se propala a respeito é mera repetição, citada por ouvir dizer". LEMOS, op. cit., p. 86; p. 91.

${ }^{25}$ A chegada de Pedro José Neto aos Sertões de Araraquara ocorreu em 1807, e não em 1790, como apontam alguns autores.

${ }^{26}$ Os dados do recenseamento de 1809 estão citados em: LEMOS, op. cit., p. 97.

${ }^{27}$ TELAROLLI, Rodolpho. Para uma história de Araraquara: 1800 a 2000. Araraquara: FCL/UNESP, Laboratório Editorial, 2003, p. 24.

${ }^{28}$ De acordo com sua certidão de casamento, publicada por Lemos, Pedro José Neto é natural de Nossa
} 
e no fato de sua suposta fuga ter ocorrido por volta de 1790, um ano após a Inconfidência Mineira, o autor aventa a possibilidade de Pedro José Neto ser perseguido das autoridades coloniais em razão de sua participação na famosa revolta. É digno de nota o fato de o próprio autor advertir que "Não há, porém, registros oficiais que permitam defender a hipótese desse nobre motivo de fuga" ${ }^{29}$ Porém, por mais que se mostrasse infundada e absurda, essa especulação fora levada a sério e transformada em verdade pelos ufanistas de plantão - sempre ávidos por enobrecer os personagens e a história da localidade. Como consequência, Pedro José Neto teria tido então uma honrosa participação na luta pela independência do Brasil ao lado de Tiradentes, personagem transformado em herói nacional pelos republicanos após a proclamação da república em $1889 .{ }^{30}$ Não é difícil imaginar o quanto isso vem contribuindo para consolidar Pedro José Neto como herói regional e, por extensão, para enobrecer a história dos sertões e do município de Araraquara.

Assim como Telarolli, a maioria dos autores que escreveram sobre a história de Pedro José Neto se equivocou a respeito do ano de sua chegada aos Sertões de Araraquara. Comprovadamente, ele não veio em 1790, como apontam esses autores, mas sim em 1807, como deixam claro as informações fornecidas pelo próprio posseiro no requerimento de sua carta de sesmaria, efetuado em 1809. ${ }^{31}$ Apenas esse dado já seria suficiente para contestar a suposta participação como inconfidente.

A saga fantasiosa não para por aí. A história de Pedro José Neto nos Sertões de Araraquara é marcada por outro equívoco que, de tanto ser repetido, se consolidou como verdade. De acordo com a versão consagrada, Pedro José Neto teria se apossado de um enorme território nos Sertões de Araraquara ${ }^{32}$, área que depois daria origem a cerca de sete sesmarias: Ouro, Rancho Queimado, Cruzes, Lageado, Cambuy, Bonfim e Monte Alegre. Posteriormente, para conseguir o perdão da Justiça ele teria então sido forçado a doar a maior parte de suas terras a seus supostos protetores, homens de poder que o livrariam dos problemas com a Justiça de Itu.

\footnotetext{
Senhora da Piedade de Inhomerim, Bispado do Rio de Janeiro. LEMOS, op. cit., pp. 79-80.

${ }^{29}$ TELAROLLI, op. cit., p. 24.

${ }^{30}$ A respeito da construção de Tiradentes enquanto herói nacional pelos republicanos ver: CARVALHO, José Murilo de. A formação das almas: o imaginário da república no Brasil. São Paulo: Companhia das Letras, 1990.

${ }^{31}$ LEMOS, op. cit., pp. 79-95.

${ }^{32}$ De acordo com as informações fornecidas por Almeida, a região supostamente apossada por Pedro José Neto englobaria uma extensa faixa de terras que se estenderia pelos atuais municípios de São Carlos, Araraquara, Gavião Peixoto, Nova Europa, Nova Esperança e Jaboticabal. ALMEIDA, op. cit.
} 
No entanto, a condição de posseiro sequer dava a Pedro José Neto o direito legal sobre as terras onde cultivava e criava algumas cabeças de gado, quanto mais poder para se colocar como portador de direito sobre terras que não explorava e que excedia exageradamente as suas condições de torná-las produtivas. A esse respeito, vale lembrar que Pedro José Neto era um homem de poucos recursos. Até 1812 não possuía sequer escravos, somente no recenseamento de 1813 ele aparece como proprietário de quatro escravos, diminuindo para dois em $1814 .^{33}$ Por outro lado, não é crível que aqueles que adquiriram sesmarias nas supostas terras apossadas por Pedro José Neto, homens oriundos da classe dominante da capitania de São Paulo, precisassem negociar com um posseiro para se tornar proprietários de terras nos Sertões de Araraquara. É revelador a esse respeito o fato de nenhum dos autores que defende essa versão apresentar provas documentais de que Pedro José Neto tenha tido algum poder efetivo sobre as alegadas terras e que as tenham transferido a outros.

Provavelmente, o fato de Pedro José Neto ter servido de informante a respeito da disponibilidade e características das terras devolutas dos Sertões de Araraquara, quando de sua ida a Itu para legalizar uma posse, em 1809, tenha induzido os primeiros autores que abordaram o tema a supor e defender que ele tivesse então cedido a maior parte de suas terras a poderosos em troca de uma suposta absolvição junto à Justiça. Mesmo porque, é justamente a partir desse momento que os pedidos de sesmarias na região aumentaram consideravelmente, sendo a maioria desses pedidos efetuados por moradores das vilas de Itu e Piracicaba.

De fato, Pedro José Neto não teve o domínio possessório reconhecido que lhe é atribuído sobre o enorme território que depois viria a ser ocupado pelas sesmarias do Ouro, Rancho Queimado, Cruzes, Lageado, Cambuy, Bonfim e Monte Alegre. A dificuldade enfrentada por ele para conseguir legalizar, mediante carta de sesmaria, uma propriedade muito menor que aquela que muitos lhe atribuem o domínio demonstra, de maneira elucidativa, a fragilidade da sua condição de posseiro pobre.

Conhecedor das dificuldades que um posseiro pobre tinha para conseguir carta de sesmaria sobre terras apossada, Pedro José Neto resolveu pedir a concessão não apenas no seu nome, mas em conjunto com seus dois filhos. Conforme mostraremos, somente após enfrentar várias dificuldades e um longo período de espera, a ele e seus filhos foi concedida uma carta de sesmaria

${ }^{33}$ As informações sobre os censos citados foram publicadas por LEMOS, op. cit., pp. 97-100. 
cuja gleba era muito menor que a maioria das sesmarias doadas na região. A concessão da gleba de maior extensão por eles pleiteada foi negada sob a alegação de que não tinham condições de cultivá-la. Comparado com as cartas de sesmarias concedidas nos Sertões de Araraquara aos membros da classe dominante de Campinas, Itu, Porto Feliz, Piracicaba e outras localidades, o processo de concessão a Pedro José Neto e seus filhos foi também muito mais difícil e moroso.

Receosos da fragilidade da condição de posseiros, em 26 de agosto de 1809 Pedro José Neto e seus dois filhos entraram com o requerimento de sesmaria nos Sertões de Araraquara na Câmara de Itu. Em resposta aos documentos enviados pela Câmara de Itu, o Procurador da Coroa e Fazenda, José Arouche de Toledo Rendon, solicitou aos vereadores dessa vila maiores informações sobre a capacidade econômica dos requerentes, advertindo que, caso seus recursos não fossem julgados satisfatórios, a solicitação seria indeferida. E acrescentou também a seguinte advertência: "deve ver que a súplica é em nome de três, para informar sôbre o estado de fortuna de cada um deles". ${ }^{34}$

Em resposta à solicitação do procurador, a Câmara de Itu enviou documento informando o seguinte:

[...] somos a dizer que os suplicantes Pedro José Neto, José da Silva e Joaquim Ferreira Neto, da Capitania de Minas Gerais se passaram ao sertão de Araraquara há três anos, onde com ânimo e constância se entranharam mais que todos. Ali arranchados sem prejuízo de terceiro, como nos afirmam pessoas fidedignas, continuam a sua lavoura e criação de gado, que ao todo são 70 ou 80 cabeças. Ainda que pobres são muito trabalhadores e capazes de estabelecer com utilidade a fazenda pretendida, para o que é próprio aquêle terreno, pois tem mostrado a experiência que neste gênero mais aproveita a diligência pessoal dos pobres do que a fôrça dos ricos, que confiam a escravos ou fazendeiros [administradores de fazendas]. [grifo do autor]. ${ }^{35}$

Como se pode observar no documento, havia um esforço dos vereadores da Vila de Itu em argumentar a favor de Pedro José Neto. Isso porque interessava a esses membros da elite de Itu continuar a tirar proveito da presença de José Neto nos Sertões de Araraquara, um informante que morava e conhecia os sertões e por isso poderia mantê-los informados sobre, por exemplo, a existência e a qualidade das terras devolutas, a presença de cursos d'águas e caminhos, assim como sobre a presença de novos posseiros. Essas e outras

\footnotetext{
${ }^{34}$ Documento publicado por LEMOS, 1972, p. 81.

${ }^{35}$ Documento publicado por LEMOS, op. cit., pp. 81-82.
} 
informações seriam de grande valia como orientação para o requerimento de novas sesmarias e defesa daquelas já conquistadas.

Sobre a função de informante assumida por Pedro José Neto, vale lembrar que foi ele que informou ao sargento-mor de Itu Joaquim Duarte do Rêgo e a outros membros da classe dominante local - que logo se tornariam sesmeiros nos Sertões de Araraquara - sobre a existência de terras devolutas na região. ${ }^{36}$ Essa função de informante aparece também na declaração de Domingos Soares de Barros, anexada à solicitação de carta de sesmaria efetuada em 1812 pelo padre Francisco Novais de Magalhães:

[...] cujos campos não atendem a sesmaria de Pedro José Neto e seus filhos e outros sesmeiros que pediram nas sobras daqueles, e certifico por presenciar que o mesmo Pedro Neto foi quem induziu ao Pe. [padre] para se arranchar no lugar em que se acha estabelecido, e por ter ouvido ao mesmo Neto e outros sei que tem campos donde se possa inteirar a sua sesmaria sem prejudicar a pessoa alguma $[\ldots] \cdot{ }^{37}$

No dia primeiro de janeiro de 1810, o Procurador da Coroa e Fazenda emitiu parecer favorável à concessão de carta de sesmaria a Pedro José Neto e seus dois filhos, porém, com uma significativa mudança, o seu tamanho foi reduzido para um terço do que havia sido pleiteado pelo posseiro. Seriam concedidas, portanto, não três léguas por três, como haviam solicitado, mas apenas três léguas por uma.

Pôsto que a câmara informe que os Suplicantes são pobres, estão contudo nos termos de se lhes conceder sesmaria no lugar que pedem, ponderando-se que são três sócios, que ali se acham estabelecidos, que são campos, e que é sertão despovoado. Porém nem porisso se lhes deve conceder três léguas de testada com três de fundo, que fazem nove léguas quadradas. Segundo as Ordens, não se lhes deve conceder senão as três léguas de testada, na forma confrontada, com uma de sertão. ${ }^{38}$

Somente no dia 7 de junho de 1811 foi então emitida a carta de sesmaria pelo então governador de São Paulo, Antônio José da Franca e Horta. Mesmo se tratando de uma gleba já apossada, a carta de sesmaria reproduz o texto padrão da época no que se refere às obrigações dos donatários, impondo-lhes, dentre outros deveres, as obrigações de cultivo, de registrar a carta no prazo de dois anos junto à Coroa portuguesa e de medir e demarcar judicialmente as

\footnotetext{
${ }^{36}$ Ibidem, p. 105.

${ }^{37}$ Além de Lemos, também Corrêa faz referência à função de informante exercida por Pedro José Neto nos Sertões de Araraquara. LEMOS, op. cit., p. 108 e CORRÊA, op. cit.

${ }^{38}$ Documento publicado por LEMOS, op. cit., pp. 81-82.
} 
fronteiras da gleba recebida antes de tomar posse da mesma. Sobre o dever de cultivar a terra, entretanto, a carta acrescenta as especificações estabelecidas pela Secretaria do Estado dos Negócios da Marinha e Domínios Ultramarinos de 1801, ou seja, a obrigação dos sesmeiros lavrarem com arado a cada ano "um pedaço de terreno de seis braças de frente e seis de fundo" sob pena de multa no valor de "cem réis por cada braça que deixarem de lavrar", reafirmando, por fim, o direito da Coroa retomar a sesmaria doada em caso de descumprimento das obrigações previstas na carta de doação.

A conquista de carta de sesmarias por posseiro de poucos recursos, como Pedro José Neto, é um caso raro nos Sertões de Araraquara. A historiografia regional cita apenas mais um caso. ${ }^{39}$

Nessa região, a maior parte das sesmarias foi concedida para donatários pertencentes à classe dominante de São Paulo, Campinas, Sorocaba, Itu, Jundiaí, Piracicaba e Porto Feliz. Eram fazendeiros, grandes comerciantes, importantes funcionários públicos e autoridades militares que utilizaram a influência que tinham junto às instâncias de poder para se tornarem grandes latifundiários na região. Expropriando posseiros pobres e conseguindo cartas de sesmaria sem grandes dificuldades, esses membros da classe dominante se tornaram proprietários de glebas na região que ultrapassavam em grande medida a sua capacidade produtiva. Muitos receberam mais de uma sesmaria. Alguns, utilizando-se de "testas de ferro", da estratégia do pedido em conjunto, e do próprio prestígio pessoal, além da disseminada prática do apossamento, conseguiram várias concessões. ${ }^{40}$

\section{Conclusão}

Na busca pelo objetivo de reescrever a história de Pedro José Neto nos Sertões de Araraquara, percebemos que a historiografia amadora, baseando-se em especulações e hipóteses infundadas, transformou esse posseiro num mito, uma espécie de herói da região, celebrado sobretudo em Araraquara, já que a ele foi conferido o título de fundador dessa cidade.

Desprendida de intenções interpretativas e de preocupações científicas, essa versão histórica amadora se converteu numa espécie de "história oficial", tão irredutível quão verdadeira em si mesma.

Apesar de todos esses problemas, as informações e a documentação reproduzida nas obras dos escritores amadores locais nos possibilitou construir

\footnotetext{
${ }^{39}$ TRUZZI; FOLLIS, op. cit.

${ }^{40}$ Ibidem.
} 
e fundamentar uma nova versão sobre a trajetória desse posseiro nos Sertões de Araraquara, o que significou também desconstruir o mito criado em torno desse personagem.

Pudemos refutar muitas das afirmações consagradas na historiografia regional sobre Pedro José Neto. Nesse sentido, não há nada que confirme a versão de que Pedro José Neto tivesse vindo em fuga para os Sertões de Araraquara depois de ter sido supostamente condenado a degredo em Piracicaba pela justiça de Itu. A documentação contraria também a alegação de que ele era um foragido da Coroa Portuguesa em razão de ter participado na Inconfidência Mineira.

Conforme expomos, também são equivocadas as afirmações de que Pedro José Neto tivesse se tornado proprietário de enormes extensões de terras na região, e que tenha negociado essas terras em troca de sua absolvição. Não foi localizado nenhum documento que comprove ou mesmo forneça indícios de que isso tenha, de fato, ocorrido. Ao contrário disso, os documentos demonstram que Pedro José Neto não tinha recursos e poder para tanto, tendo enfrentado dificuldades até mesmo para legalizar, mediante carta de sesmarias, uma pequena gleba de terras na região, e de tamanho muito inferior àquela que havia requerido, juntamente com seus dois filhos, às autoridades. Ressalta-se ainda que a solicitação fora até mesmo ameaçada de indeferimento pela autoridade colonial responsável, e que a sesmaria somente fora concedida o posseiro contou com a colaboração dos vereadores da cidade de Itu. A sesmaria concedida a Pedro José Neto e seus filhos, tinha uma extensão bem inferior que a maioria das sesmarias concedidas na região aos homens abastados e de reconhecido prestígio político e social.

Para nós, a consolidação no cenário regional de uma versão histórica tendenciosa sobre a trajetória do posseiro Pedro José Neto nos Sertões de Araraquara reflete as características de grande parte da nossa historiografia amadora regional ou local, sempre pronta para glorificar os acontecimentos de seu passado e as ações de seus agentes históricos eleitos protagonistas. No caso de Pedro José Neto, tal construção ganhou peso pelo fato do mesmo ter sido intitulado o fundador da cidade de Araraquara. A esse respeito ressaltamos que existe uma inclinação ufanista dos historiadores amadores regionais em construir e glorificar os homens eleitos protagonistas, transformando-os em verdadeiros heróis locais ou regionais, sejam eles heróis fundadores, civilizadores, ou do progresso.

Analisando as fontes documentais e as informações publicadas em textos sobre os Sertões de Araraquara, pudemos constatar que Pedro José Neto 
fora, de fato, um dos primeiros posseiros dessa região, tendo se constituído num informante sobre as características desses extensos sertões aos membros da classe dominante de Itu, que estavam interessados em adquirir sesmarias nesse território até então muito pouco conhecido, mas que já se aproximava da franja agrícola. Isso lhe possibilitou contar com o apoio desses poderosos na conquista de sua carta de sesmaria.

Ao inserirmos nossa reflexão no contexto mais amplo da história da apropriação da terra no Brasil colonial, a trajetória de Pedro José Neto nos Sertões de Araraquara nos permite assinalar que os homens modestos que se tornaram posseiros no interior do território colonial não assistiram passivamente a expropriação de suas terras pelos mais poderosos, mas lutaram - no limite de suas forças e condições - para assegurá-las, sendo uma das estratégias utilizadas a busca da legalização mediante a conquista de carta de sesmarias sobre as terras apossadas.

Artigo recebido para publicação em 28/07/2015

Artigo aprovado para publicação em 05/02/2016 